\title{
Teoria de Vygotsky: reflexões sobre o uso do ambiente virtual de aprendizagem e da Resolução de Problemas no Ensino de Química
}

Vygotsky's Theory: reflections on the use of virtual learning environment and Problem Solving in Chemistry Teaching

Teoría de Vygotsky: reflexiones sobre el uso del entorno virtual de aprendizaje y la Resolución de Problemas en la Enseñanza de la Química

\section{Resumo}

Para o Ensino de Química e outras áreas do conhecimento, diversas metodologias ativas podem ser aplicadas, tendo em vista o processo de aprendizado dos alunos, reforçando um comportamento proativo na busca da construção de saberes. Neste aspecto, emerge a figura de Vygotsky e a contemporaneidade de sua teoria influenciando a Educação no que tange à relação do indivíduo e o seu contexto social e cultural. Sendo assim, a finalidade deste estudo é trazer uma reflexão sobre a teoria de Vygotsky no uso da metodologia de ensino de Resolução de Problemas em um Ambiente Virtual de Aprendizagem na área do Ensino de Química. A metodologia usada foi de um arcabouço bibliográfico de artigos e os resultados apontam que o interacionismo contribui de forma satisfatória nas discussões envolvidas nos processos pedagógicos. Também pode-se apontar que a metodologia de Resolução de Problemas implementada através de um Ambiente Virtual de Aprendizagem é uma estratégia desafiadora para ensinar Química de uma forma que o aluno consiga entender os problemas e interpretá-lo utilizando o Ambiente Virtual de Aprendizagem para dialogar com seus colegas e professores sobre as soluções de uma dada situação.

Palavras-chave: Ensino de química; Teoria de Vygotsky; Ambiente virtual de aprendizagem; Resolução de problemas; Teoria de aprendizagem.

\begin{abstract}
For chemistry teaching and other areas of knowledge, several active methodologies can be applied, in view of the students' learning process, reinforcing a proactive behavior in the search for the construction of knowledge. In this aspect, the figure of Vygotsky emerges and the contemporaneity of his theory influencing Education with regard to the relationship of the individual and its social and cultural context. Thus, the purpose of this study is to bring a reflection on Vygotsky's theory in the use of problem solving teaching methodology in a Virtual Learning Environment in the area of Chemistry Teaching. The methodology used was a bibliographic framework of articles and the results indicate that interactionism contributes satisfactorily to the discussions involved in pedagogical processes. It can also be pointed out that the Problem Solving methodology implemented through a Virtual Learning Environment is a challenging strategy to teach Chemistry in a way that students can understand the problems and interpret it using the Virtual Learning Environment to dialogue with their colleagues and teachers about the solutions of a given situation.
\end{abstract}

Keywords: Chemistry teaching; Vygotsky theory; Virtual learning environment; Problem resolution; Learning theory.

\section{Resumen}

Para la enseñanza de la química y otras áreas del conocimiento, se pueden aplicar varias metodologías activas, en vista del proceso de aprendizaje de los estudiantes, reforzando un comportamiento proactivo en la búsqueda de la construcción del conocimiento. En este aspecto, surge la figura de Vygotsky y la contemporaneidad de su teoría influye en la Educación con respecto a la relación del individuo y su contexto social y cultural. Por lo tanto, el propósito de este estudio es traer una reflexión sobre la teoría de Vygotsky en el uso de la metodología de enseñanza de resolución de problemas en un Entorno Virtual de Aprendizaje en el área de Enseñanza de la Química. La metodología utilizada fue un marco bibliográfico de artículos y los resultados indican que el interaccionismo contribuye satisfactoriamente a las discusiones involucradas en los procesos pedagógicos. También se puede señalar que la metodología de Resolución de 
Problemas implementada a través de un Entorno Virtual de Aprendizaje es una estrategia desafiante para enseñar Química de manera que los estudiantes puedan comprender los problemas e interpretarlos utilizando el Entorno Virtual de Aprendizaje para dialogar con sus colegas y profesores sobre las soluciones de una situación dada.

Palabras clave: Enseñanza de la química; Teoría de Vygotsky; Entorno virtual de aprendizaje; Resolución de problemas; Teoría del aprendizaje.

\section{Introdução}

A utilização das ferramentas tecnológicas no Ensino de Química, deve explicitar seu caráter dinâmico a fim de que o conhecimento químico seja expandido, não como um conjunto de conhecimentos isolados, prontos e acabados, mas como um conjunto de ensinamentos interativos que envolvem a interdisciplinaridade, a contextualização e a tecnologia, possibilitando a construção de conhecimentos voltados para a vida (Lima \& Moita, 2011). Partindo dessa constatação, o Ensino de Química pode ampliar seus conceitos de abordagens didáticas com a adoção da metodologia Resolução de Problemas associado ao uso de Ambiente Virtual de Aprendizagem, tendo em vista que este ambiente incentiva as interações entre os alunos e com o professor desenvolvendo os processos dinâmicos de refletir, interpretar, tomar decisões e gerir os contextos de aprendizagens.

Neste aspecto, emerge a figura de Vygotsky e a contemporaneidade de sua teoria influenciando a Educação no que tange à relação do indivíduo e o seu contexto social e cultural. Assim, neste manuscrito apresenta-se as considerações sobre Vygotsky, sua teoria e linhas de pensamento; os níveis de desenvolvimento que o indivíduo pode passar para a aquisição do conhecimento; os instrumentos e signos na perspectiva de Vygotsky; como a inteligência se desenvolve; as principais contribuições do autor na educação; a metodologia de Resolução de Problemas (RP) na aprendizagem sob a perspectiva sociointeracionista; a relação de Vygotsky com o desenvolvimento do aluno em um Ambiente Virtual de Aprendizagem (AVA) e o Ensino de Química em uma abordagem sociointeracionista.

\section{Considerações sobre Vygotsky}

Vygotsky nasceu na Rússia em 1896. Ele se formou na Faculdade de Direito da Universidade de Moscou e mais tarde se dedicou aos estudos literários. Entre 1917 e 1923, atuou como professor e pesquisador nas áreas de Arte, Literatura e Psicologia. A partir de 1924, ele aprofundou suas pesquisas no campo da Psicologia em Moscou e se voltou para a educação de deficientes. Entre 1925 e 1934, trabalhou com outros cientistas para desenvolver pesquisas psicológicas envolvendo anormalidades físicas e mentais. Depois de concluir outro curso de Medicina, ele foi convidado para servir como chefe do Departamento de Psicologia do Instituto Soviético de Medicina Experimental. Morreu em 1934 (Brito, 2013).

Lev Semionovitch Vigotski na transliteração Lev Semyonovich Vygotskij, sendo o sobrenome também transliterado como Vigotski, Vygotski ou Vygotsky, deu trajetória aos processos de pensamento, resoluções de problemas, interação e construção de significado que contribuem para o desenvolvimento da sociedade humana e que originou uma corrente de pensamento sócio construtivista (Yasnitsky, 2018). Por ter vivido a Revolução Russa (1917) suas obras só foram conhecidas e valorizadas mais recentemente. Nota-se que apesar de ser formado em Direito, sua primeira obra que o conduziu para a área da Psicologia da Arte (1925). Ademais, seu interesse pelas funções mentais superiores, cultura e linguagem o levaram a trabalhar na obra "A formação social da mente" abordando os processos psicológicos a partir da infância e do contexto histórico-cultural. Autor de mais de 200 obras que enfatiza o papel da cultura, estimulada pela interação entre parceiros sociais e mediada pela linguagem, no processo de cognição.

A vida de Vygotsky foi tragicamente interrompida em 11 de junho de 1934, quando ele faleceu de tuberculose aos 37 anos. Mesmo assim, Vygotsky é considerado um pensador formador em Psicologia e muito de seu trabalho ainda está sendo descoberto e explorado ao longo dos anos (Tunes, Tacca \& Bartholo, 2005). 
De acordo com Vygotsky, todas as atividades cognitivas fundamentais tomam forma em uma matriz da história social e formam os produtos do desenvolvimento sócio histórico (Luria, 1976), ou seja, as habilidades cognitivas e os padrões de pensamento não são determinados, principalmente por fatores inatos, mas são produtos das atividades praticadas nas instituições sociais da cultura em que o indivíduo cresce.

Consequentemente, a história da sociedade em que a criança é criada e a família e a história pessoal da criança são determinantes cruciais da maneira como esse indivíduo pensará. Nesse processo de desenvolvimento cognitivo, a linguagem é uma ferramenta crucial para determinar como a criança aprenderá a pensar, porque modos avançados de pensamento são transmitidos à criança por meio de palavras (Toassa, 2013).

Para Vygotsky, uma compreensão clara das inter-relações entre pensamento e linguagem é necessária para a compreensão do desenvolvimento intelectual. A linguagem não é apenas uma expressão do conhecimento que a criança adquiriu. Há uma correspondência fundamental entre pensamento e fala em termos de um prover recursos para o outro, a linguagem tornase essencial na formação do pensamento, determinando características de personalidade e exercendo influência sobre a cognição. A teoria de Vygotsky se aproxima da hipótese Sapir-Whorf de que a estrutura da linguagem que se usa habitualmente influencia a maneira como ele percebe seu ambiente (Baquero, 2001).

A teoria pode ser enunciada sob os seguintes aspectos: sociabilidade do homem, interação social, signo e instrumento, cultura, história, e funções mentais superiores, por isso, pode-se dizer que a teoria de Vygotsky é sócio-histórico-cultural do desenvolvimento das funções mentais superiores, mas, frequentemente, apontada como teoria histórico-cultural.

Na concepção de Vygotsky (1984), a principal característica do ser humano é a habilidade social. Em sua época, esse princípio não passava de uma hipótese puramente teórica. No entanto, atualmente, pode-se dizer que, devido à fusão dos dois métodos de pesquisa, os argumentos sociais básicos (determinados em parte pela genética) têm quase as mesmas leis escritas dos fatos científicos. Estudos empíricos recentes sobre o desenvolvimento social de crianças pequenas provaram plenamente a tese das habilidades sociais principais e iniciais (Brito, 2013).

\section{Teorias e Linhas de Pensamento de Vygotsky}

A teoria de Vygotsky nomeou-se como sócio-construtivismo e tem como escopo o desenvolvimento humano e a aprendizagem. Os conceitos desenvolvidos por Vygotsky transcenderam o tempo e as fronteiras geográficas. Hoje, seu trabalho é amplamente aplicado a muitos campos de investigação, desde a Psicologia à Educação de Línguas. Embora essa adoção do pensamento do psicólogo soviético seja um motivo de celebração, estudiosos enfatizam a falta de aplicação do pensamento Vygotskyano à pesquisa psicológica contemporânea (Tunes, Tacca \& Bartholo, 2005).

É no crescimento das crianças, principalmente na primeira infância, que a interação assimétrica surge, ou seja, comunicam-se com os adultos e transportam todas as informações culturais. Neste tipo de interação, os papéis básicos correspondem a diferentes sistemas de símbolos. Do ponto de vista da genética, os sistemas de símbolos têm primeiro funções de comunicação e depois funções pessoais: eles passam a ser usados para organizar e controlar indivíduos (Leão, Quartieri \& Marchi, 2013).

Este é precisamente o elemento básico do conceito de interação social de Vygotsky, que desempenha um papel formativo e construtivo no processo de desenvolvimento. Assim, a aprendizagem consiste na relação com o mundo social. A formação é o resultado do relacionamento com pais, irmãos, colegas e demais indivíduos (De Azevedo, 2013).

Portanto, a participação da família no desempenho da aprendizagem é a base para incorporar novos valores no processo e ser capaz de superar todos os obstáculos que lhes são impostos. Vygotsky usa esses argumentos em suas obras para descrever as relações pessoais/sociais, afirmando que não há características humanas desde o nascimento, tampouco resultado de pressão externa (De Azevedo, 2013). 
São frutos da interação homem/sociedade, pois quando um homem muda seu ambiente em busca das necessidades básicas, ele mudará a si mesmo. As crianças têm apenas funções psicológicas básicas quando nascem da aprendizagem cultural. Essas funções tornam-se funções psicológicas avançadas. Elas são o controle consciente do comportamento, as ações conscientes relacionadas às características do comportamento e a liberdade pessoal. O desenvolvimento da psicologia humana é sempre mediado por outro meio que instrui, define e dá significado prático. Desse modo, os membros imaturos do ser humano vão se adaptando gradativamente aos modelos mentais de função, comportamento e cultura (Lopes, 2016).

Nesse caso, pode-se citar a importância da tolerância de fato: as crianças com deficiência interagem com as crianças em maior desenvolvimento, trocam conhecimentos e experiências e passam a aprender juntas. Vygotsky (1989) defende educação inclusiva e acessibilidade para todos. Devido ao processo criativo envolvendo domínio natural, ferramentas e o uso de ferramentas, as pessoas podem realizar planos de ação indireta com ou sem deficiência (Aragão \& Silva, 2012).

Pessoas com deficiência auditiva, visual e outras deficiências podem ter um alto nível de desenvolvimento e com as escolas promovendo a inclusão com a linguagem de sinais Libras, e materiais necessários para que possam desenvolver habilidades de leitura e superar seus conhecimentos diários. Crianças cegas podem atingir o mesmo desenvolvimento que crianças normais, mas de outra forma, é importante que os educadores entendam essa particularidade, que é a lei da compensação (Aragão \& Silva, 2012).

A limitação biológica não é o motivo que determina os surdos e o subdesenvolvimento dos cegos. A sociedade cria esses limites para que o deficiente não possa se desenvolver plenamente. $\mathrm{O}$ segundo tipo refere-se às origens culturais das funções psicológicas, que se originam das relações pessoais e de suas origens sociais e culturais. Isso mostra que a cultura é complemento da condição humana, porque o desenvolvimento intelectual humano não é negativo, tampouco independente do desenvolvimento histórico e das formas de vida social (Rego, 2001).

O desenvolvimento psicológico das crianças é um processo contínuo de aquisição, desenvolvimento da inteligência e da linguagem relacionado à fala e ao pensamento interno. Ao impor a estrutura da multiplicação, o aprendizado de novos conceitos pode impedir que a criança organize todos os que já possui.

O propósito de Vygotsky é observar como as funções mentais, como memória, atenção, percepção e pensamento aparecem pela primeira vez na forma principal e depois na forma superior. Assim, é possível perceber diferenças importantes entre funções básicas (compartilhadas por animais e humanos) e funções mentais superiores (especialmente relacionadas a humanos). No que diz respeito à contribuição de Vygotsky, o desenvolvimento se baseia na relação que se estabelece entre o indivíduo e o meio social. Essa relação não é direta, mas mediada por um sistema de símbolos, em que a linguagem desempenha um papel central (Astolfi \& Develay, 2014).

A linguagem é o sistema simbólico básico dos seres vivos. Com isso, a ampliação da linguagem e sua relação com o pensamento ocupam uma posição central nas obras de Vygotsky. O autor tem duas funções a serem destacadas: função de comunicação social e função de pensamento generalizado. A função da comunicação social refere-se à criação de um sistema de linguagem para se comunicar com terceiros. Em outras palavras, essa é a necessidade de comunicação (Astolfi \& Develay, 2014).

Todavia, para se comunicar de forma eficaz, não basta mostrar estados gerais como "desconforto" ou "prazer". Devem ser usados sinais que outras pessoas possam entender. Esses sinais podem traduzir com precisão pensamentos, sentimentos e desejos. Os indivíduos têm experiências complexas e especiais que devem ser simplificadas e generalizadas antes que possam ser transformadas em signos e transmitidas a outros. Esse fenômeno produz a segunda função da linguagem: a função de generalização do pensamento (Lima \& Leite, 2012).

Nessa perspectiva, a linguagem agrupa coisas reais, agrupando todas as ocorrências do mesmo tipo de objetos, eventos e situações na mesma categoria conceitual. Nesse caso, a função do pensamento generalizado torna a linguagem uma ferramenta 
de pensamento. A origem e o desenvolvimento do pensamento e da linguagem são diferentes e independentes, mas, em algum ponto, há uma conexão estreita entre esses dois fenômenos.

Porém, antes desse fenômeno de conexão, o desenvolvimento do pensamento em crianças é a fase pré-fala, e o desenvolvimento da linguagem, a fase pré-intelectual. Antes de dominar a língua, as crianças tentam solucionar os problemas práticos e usar meios e ferramentas para atingir seus objetivos. Embora a criança não domine o sistema de símbolos da linguagem, ela usa a expressão verbal, como o choro e o riso (Souza, 2011).

Em torno de dois anos de idade, com a integração do pensamento e da linguagem, uma nova forma de função mental começou a aparecer. Nesse sentido, a fala passa a ser um intelectual com função de simbolização e generalização, enquanto o pensamento passa a ser a expressão linguística do significado dado pela linguagem (Rabello, Passos \& Silveira, 2011).

Ao interagir com pessoas mais maduras na cultura (ou seja, pessoas com linguagem estruturada), o indivíduo pode dar um salto qualitativo no pensamento oral. Nessa perspectiva, quando o processo de desenvolvimento do pensamento e da linguagem se combinam, é possível ao ser humano mediar padrões de função mental mais complexos por meio do sistema de símbolos da linguagem (Rabello, Passos \& Silveira, 2011).

Por meio da brincadeira, a aprendizagem das crianças em sala de aula, o ensino divertido e a Educação Infantil estão interligados e se tornam a porta de entrada para a aprendizagem das crianças. Brincar em todas as fases torna-se importante para a aprendizagem na infância. As pessoas perceberam que, principalmente, na fase final da Educação Infantil, os professores buscam a alfabetização das crianças e a redução do espaço lúdico, o que tem despertado grande atenção (Morais et al., 2021).

É necessário que os professores trabalhem, mas eles devem ser lúdicos e coordenados, para que possam realizar um trabalho centrado na criança, de forma a colaborar para melhor educar as mesmas. Daí a importância da utilização dos espaços internos e externos da escola para as atividades educativas, organizando e proporcionando o conhecimento que cada criança já possui (Pérez \& Carvalho, 2012).

Os jogos foram identificados como um espaço privilegiado para o desenvolvimento infantil. Porém, no ensino o que acontece com frequência e acaba dando espaço para outras atividades aos educadores é mais importante. Vygotsky (1998) desempenha um papel importante no processo de reproduzir os pensamentos das crianças. Segundo ele, por meio de brincadeiras, os alunos reproduzem palavras externas e as tornam públicas, estabelecendo assim o seu pensamento (Pérez \& Carvalho, 2012).

Segundo o pensamento de Vygotsky, as ações e os pensamentos inteligentes (pensar, refletir, significar, organizar e outros), são formados no decurso de sua história social. Sob este viés, os pilares desta teoria de aprendizagem são (Stadler et al.,2004): i) as funções psicológicas têm amparo biológico, pois são provenientes da atividade cerebral; ii) o funcionamento psicológico tem como base as relações sociais dentro de um contexto histórico; iii) a cultura é parte essencial do processo de construção da natureza humana; iv) a interação entre o homem e sociedade é mediada por sistemas simbólicos, que auxiliam a atividade humana.

Os estudiosos que trabalham em campos interdisciplinares acreditam no potencial para aplicações mais amplas do trabalho de Vygotsky. A intenção não é delinear o projeto Vygotskyano em sua totalidade, já que sua pesquisa abrangeu tópicos que vão desde os aspectos clínicos do desenvolvimento até os aspectos aplicados das práticas educacionais, tampouco fornecem uma aplicação matizada do trabalho de Vygotsky a questões de pesquisa específicas, como também não apresenta uma revisão detalhada de como o trabalho de Vygotsky foi implementado anteriormente (Zanella, 2001).

Vygotsky visualizou o sucesso da Psicologia como uma Ciência apenas se ela sustentasse sua natureza holística e interdisciplinar. Esse sistema [de uma psicologia holística interdisciplinar] ainda não foi criado. Pode-se dizer com certeza que não surgirá das ruínas da Psicologia empírica ou dos laboratórios dos reflexologistas. Ele virá como uma ampla síntese biossocial da teoria do comportamento animal e do homem social (Coelho et al., 2012). 
Essa nova Psicologia será um ramo da Biologia Geral e, ao mesmo tempo, a base de todas as Ciências Sociológicas. Será o nó que une a Ciência da Natureza e a Ciência do Homem. Estará, portanto, de fato, mais intimamente conectado com a Filosofia estritamente científica que representa a teoria combinada do conhecimento científico e não com a Filosofia especulativa que precedeu as generalizações científicas (Vygotsky, 1991).

\section{Níveis de Desenvolvimento do Indivíduo}

Para Vygotsky (1998) há dois níveis de desenvolvimento que o indivíduo pode atingir. Um deles é denominado "real", aquele já adquirido ou formado, que determina que a criança já pode ser capaz de fazer por si própria, e um "potencial", aquele em que a criança aprende com outra pessoa. Em relação à Vygotsky, o desenvolvimento potencial é mais significativo no desenvolvimento da criança que de desenvolvimento real (Souza \& Rosso, 2011). Infere-se que o aprendizado se relaciona com o desenvolvimento, produzindo a distância entre aquilo que a criança faz sozinha e o que ela é apta a fazer com a intermédio de um adulto, estando ambos os processos aprendizagem e desenvolvimento inter-relacionados.

A teoria de Vygotsky (1962) propõe que o desenvolvimento da criança seja melhor compreendido em relação à experiência social e cultural. A interação social, em particular, é vista como uma força crítica no desenvolvimento. Por meio do auxílio de pessoas mais experientes no meio social, a criança aprende gradativamente a funcionar intelectualmente por conta própria. Assim, o mundo social medeia o desenvolvimento cognitivo individual.

Ao enfatizar a natureza socialmente mediada dos processos cognitivos, essa abordagem oferece novas maneiras de avaliar o potencial cognitivo das crianças e de ensinar leitura, Matemática e escrita. A teoria sociocultural também aumentou a apreciação da profunda importância da variação cultural no desenvolvimento. As maneiras pelas quais os adultos apoiam e direcionam o desenvolvimento infantil são influenciadas pela cultura, especialmente os valores e práticas e, organizam, o que e como adultos e crianças pensam e trabalham juntos e usam ferramentas culturais para entender o mundo e resolver problemas cognitivos (Silva, 2004).

Essas ferramentas são criadas por culturas e assumem uma variedade de formas, incluindo linguagem, símbolos matemáticos, alfabetização e tecnologia. Conforme as crianças se desenvolvem, diferentes ferramentas as ajudam a funcionar com mais eficácia na resolução de uma dada situação e na compreensão do mundo. Assim, as ferramentas de pensamento, que são produtos da cultura, passam a ser incorporadas às formas como os indivíduos pensam e agem no mundo (Rego, 2001)

De acordo com Vygotsky (1986), todas as atividades cognitivas fundamentais tomam forma em uma matriz da história social e formam os produtos do desenvolvimento sócio-histórico. Ou seja, as habilidades cognitivas e os padrões de pensamento não são determinados, principalmente por fatores inatos, mas são produtos das atividades praticadas nas instituições sociais da cultura em que o indivíduo cresce (Silva, 2004).

Consequentemente, a história da sociedade em que a criança é criada, a família e a história pessoal da criança são determinantes cruciais da maneira como esse indivíduo pensará (Coelho et al., 2012). Nesse processo de desenvolvimento cognitivo, a linguagem é uma ferramenta fundamental para determinar como a criança aprenderá a pensar, porque modos avançados de pensamento são transmitidos à criança por meio de palavras (Rego, 2001).

Ao contrário da maioria dos psicólogos de sua época, Vygotsky (1984) considerava o desenvolvimento mental como um processo de apropriação de formas superiores da psique, que são mantidas pela cultura e transmitidas à criança durante a interação com o adulto. Nesse caso, não se trata de transferência passiva de conhecimento (Tunes, Tacca \& Bartholo, 2005).

O desenvolvimento é entendido como um processo contínuo de auto movimento, o surgimento de novas propriedades e qualidades que não existiam nos estágios anteriores. Segundo Vygotsky (1984, p. 248), esse processo é determinado pela "unidade dos aspectos materiais e mentais, a unidade do social e do pessoal à medida que a criança sobe nas etapas de desenvolvimento". 
A lógica geral do desenvolvimento, sustentada por Vygotsky (1984), está associada à transformação das funções mentais naturais em funções superiores. O desenvolvimento das funções mentais superiores é garantido no processo de domínio das ferramentas da atividade mental (Moreira, 2009).

É fundamental ao explicar a natureza de um processo mental que leva à solução de um problema que deve se proceder a partir do objetivo, mas não se deve limitar apenas a ele. O objetivo não implica na explicação do processo. O principal problema relacionado ao processo de formação de conceitos e de atividade expediente em geral é um problema de ferramentas pelas quais esta ou aquela operação psíquica é realizada e esta ou aquela atividade é realizada (Vygotsky, 1982).

Sob esta perspectiva filosófica de Vygotsky, a distância entre o nível de desenvolvimento real e o potencial denominase de Zona de Desenvolvimento Proximal (ZDP). O conceito de ZDP, foi desenvolvido por Lev Semionovitch Vygotsky no final dos anos 1920 e elaborado, progressivamente, até sua morte em 1934. No desenvolvimento de processos psicológicos superiores, Vygotsky (1984) definiu a ZDP como:

A distância entre o nível de desenvolvimento real conforme determinado pela resolução independente de problemas e o nível de desenvolvimento potencial conforme determinado pela solução de problemas sob a orientação de um adulto ou em colaboração com colegas mais capazes" (Vygotsky, 1984, p. 86).

Ou seja, a ZDP foi entendida por Vygotsky (1984) para descrever o nível atual ou real de desenvolvimento do aluno e o próximo nível atingível por meio do uso de ferramentas semióticas e ambientais mediadoras. A ideia é que os indivíduos aprendam melhor quando trabalham juntos com outros durante a colaboração conjunta, e é por meio desses esforços colaborativos com pessoas mais qualificadas que os alunos aprendem e internalizam novos conceitos, ferramentas psicológicas e habilidades (Chaiklin, 2011).

O principal objetivo da educação da perspectiva Vygotskyana é manter os alunos nas próprias ZDP tão frequentemente quanto possível, dando-lhes aprendizagem interessante e culturalmente significativa e tarefas de resolver uma dada situação que são ligeiramente mais difíceis do que o que eles fazem sozinhos, de modo que eles precisarão trabalhar juntos com outro colega mais competente ou com um professor ou adulto para terminar a tarefa (Minick, 2002).

A ideia é que, depois de concluir a tarefa em conjunto, o aluno provavelmente será capaz de concluir a mesma tarefa individualmente na próxima vez e, por meio desse processo, a ZDP do aluno para essa tarefa específica terá aumentado. Este processo é então repetido no nível mais alto de dificuldade da tarefa que a nova ZDP do aluno exige (Chaiklin, 2011). Assim, o foco do ensino está nas tarefas da ZDP que o aluno não pode fazer sozinho, mas tem o potencial de realizar com a orientação de outros. À medida que o aluno realiza a tarefa, sua ZDP, ou a lacuna entre o que ele pode fazer por conta própria e o que só pode realizar com assistência, diminui.

Vygotsky (1962) introduziu o conceito de ZDP para criticar os testes baseados em psicometria nas escolas russas. O teste tradicional refletiu apenas o nível atual de realização dos alunos, ao invés do potencial do aluno para o desenvolvimento no futuro. A zona de desenvolvimento real não descreve suficientemente o desenvolvimento. Em vez disso, reflete o que já foi desenvolvido ou alcançado. O nível de desempenho assistido na ZDP destaca o potencial para comportamento emergente e “amanhã do desenvolvimento" (Vygotsky, 1978). O termo proximal indica que a assistência fornecida vai um pouco além da competência atual do aluno, complementando e construindo sobre suas habilidades existentes.

Para chegar a esta posição, Vygotsky (1986) teve que superar dois tipos de reducionismo - o biológico, que é o amadurecimento normal do cérebro físico e o sociológico, a apropriação pelo aprendiz dos bens culturais da sociedade (linguagem, etc.) impulso sobre ele por. É nesta última área que Vygotsky colocou sua ZDP, argumentando que ao invés de ter a educação se arrastando no desenvolvimento sociológico, ela deve antecipá-lo deve correr em frente enquanto o adulto ajuda o aluno a dar o próximo passo (Coelho et al., 2012). 
Vygotsky (1986) reconheceu que a distância entre fazer algo de forma independente e com a ajuda de outro indicava estágios de desenvolvimento, que não necessariamente coincidem em todas as pessoas. Desta forma, ele considerava o ensino de um aluno de um instrutor não apenas como uma fonte de informação a ser assimilada, mas como uma alavanca com a qual o pensamento do aluno, com suas características estruturais, é deslocado de nível a nível (Chaiklin, 2011). Na concepção de Vygotsky, o indivíduo é o social e o social é o indivíduo, e as estruturas sociais impactam as estruturas cognitivas de cada um.

Muitas obras de Vygotsky foram adulteradas em todo o mundo ao longo dos anos. No Brasil, esse conceito teve duas traduções: zona de desenvolvimento proximal e zona de desenvolvimento imediato ou iminente. O termo ZDP é provavelmente uma das ideias mais amplamente reconhecidas e conhecidas associadas ao legado científico de Vygotsky.

Segundo a autora Zoia Prestes (2010), os livros "Pensamento e linguagem" e "A formação social da mente", que incorporaram Vygotsky no Brasil, receptam modificações tão relevantes e precisas, que é provável enunciar que não foram registrados por ele. A ideia de zona de desenvolvimento iminente é representada por zona ZDP ou zona de desenvolvimento imediato. Prestes (2010) preserva que a compreensão que mais se ajunta do termo russo, da qual atributo primordial, em seu entendimento, é a das "possibilidades de desenvolvimento".

Como descreve a autora, ambas as palavras próxima e imediato não são suficientes para apresentar aquilo que considera importante no que diz respeito a sua conceituação. Para ela, refere-se à relação que há entre o desenvolvimento e instrução e, também, a colaboração de outrem. Prestes (2010) ainda enfatiza que se tratando de ZDP ou imediato, estes não remetem a real importância da instrução em um formato que possibilita ou não o desenvolvimento. Vygotsky não aborda a instrução como garantidor de desenvolvimento, mas para ele, sua realização em conjunto a colaboração de uma outra pessoa ou em pares, possibilita o desenvolvimento.

Na teoria de Vygotsky, o desenvolvimento é concebido como uma autopropulsão que cria novas funções psicológicas superiores por meio da reorganização das inferiores, ao mesmo tempo, sendo as funções psicológicas construções históricoculturais baseadas em funções semióticas, elas só podem vir do exterior (Minick, 2002).

Essa definição é abundante e proficiente no entendimento dos métodos de ensino na sala de aula. A zona de desenvolvimento iminente distingue-se, de acordo com Vygotsky (1998), pelo que a criança é qualificada a realizar com auxílio. Trata-se de uma zona de contingências de desenvolvimento que têm potencial de acontecer, na qual estipuladas incumbências mentais estão em sazonamento. Isso diferencia-se da compreensão de alguns tradutores que supõem precisamente o adverso, esta zona é o que as crianças podem fazer sem a mediação de um adulto. Outro erro é reputar que essa intermediação não acontece também entre as crianças (Prestes, 2012).

Uma das primeiras traduções de Vygotsky do referido conceito de é intitulado de ZDP. Outra tradução realizada por Paulo Bezerra (2004) é a zona de desenvolvimento imediato. Quando se trata deste conceito, nem as palavras proximais como a imediato transmitem o que é considerado mais importante, pois está intimamente relacionado com a relação entre desenvolvimento e ensino e o comportamento colaborativo de outra pessoa (Prestes, 2010).

Ao usar a ZDP, as pessoas deixam de perceber a importância do ensino como uma atividade que pode ou não promover o desenvolvimento. Vygotsky (1984) não defendeu que a orientação é a garantia do desenvolvimento, mas quando realizada em ação colaborativa, seja entre adultos e pares, cria possibilidades de desenvolvimento.

A ZDP é uma representação usada para argumentar a aprendizagem. Em primeira análise significa que antes da criança frequentar a escola, seu potencial é desenvolvido com trocas definidas e neste momento adquire conhecimento. A noção de desenvolvimento se direciona a uma evolução sistemática. Está nem sempre é linear e sobrevém nos aspectos afetivo, cognitivo, social, motor e as relações com o meio (Souza \& Rosso, 2011). Convém ressaltar que este é aplicado nas práticas educativas, principalmente no campo do planejamento de estratégias de ensino, em que os professores estabelecem em sala de aula interações com seus alunos. 
Pode-se exemplificar no campo da alfabetização, em que os professores registram desempenhos retrospectivos, ou seja, habilidades já consolidadas e quando se trata de desenvolvimento proximal infere-se na capacidade de realizar tarefas e resolver problemas com ajuda ou mediação de outros.

Esse panorama auxilia na análise de que é nesta ZDP que o professor deve atuar nos processos de amadurecimento dos alunos. Portanto, não basta o aluno estar em condições ideais de estudo e esperar que ele aja sozinho, deve haver intervenção do professor quando necessário a fim de elevar a qualidade de aprendizagem (Galuch \& Sforni, 2009).

\section{Instrumentos e Signos em uma Perspectiva Vygotskyana}

Vygotsky (1984), trata a função mediadora em dois tipos de elementos mediadores, os instrumentos e os signos na atividade humana, então, os signos têm seu papel como instrumentos psicológicos, no controle de atividades que se constituem em ferramentas nos processos da psique do indivíduo. O instrumento atua como o facilitador para que se alcance determinado objetivo, possibilitando ampliar a intervenção da natureza. Nota-se que no ensino aprendizagem a mediação acontece como um meio da interação com instrumentos e signos, produzido, compartilhado e acessado pelos alunos. Na linguagem simbólica nasce a formação de conceitos, uma vez que a linguagem simbólica pertence a um grupo de indivíduos e não a um indivíduo em particular. E, assim, o papel do professor e dos grupos de alunos trabalham ativamente na construção de compreensão do aprendizado.

Assim sendo, o professor se utiliza de instrumentos (meios tecnológicos, livros didáticos, espaço da sala de aula) e signos para a constituição do saber no educando. Essa constituição revela que os alunos entre si, em pequenos grupos trocam informações a respeito de um assunto específico, e depois compartilham as mesmas para que todos se apropriem do que foi abordado. Após, percebe-se o que ainda não se sabe sobre o assunto, e a partir disso formular objetivos, e procurar respondê-los para em sala de aula compartilhar o que foi aprendido, para que todos tenham conhecimento e partilhem do saber elaborado (Arruda et.al., 2019).

A aquisição de signos, como um tipo particular de ferramentas, medeia a evolução dos chamados processos psicológicos superiores no Homo sapiens, ou, as formas específicas de cognição humana, em oposição aos processos inferiores atribuídos por Vygotsky ao comportamento de outros animais (Silva, et al., 2017).

Nesse sentido, a capacidade de usar signos apareceria como uma pura res cogitans, fora da história do desenvolvimento. Como aponta Vygotsky (1986, p.6) a visão comum na época "atribuía o uso do signo à descoberta espontânea da criança da relação entre os signos e seus significados". A linguagem ou o signo linguístico, embora entendido na época como comunicativo, foi ignorado em sua função de mediador de conceito e, também, em sua função cognitiva reflexiva, ou seja, em sua função de generalizar experiências.

Vygotsky (1984) que viu a separação da atividade prática do discurso como uma crise na Psicologia, enfatiza que a análise das relações entre o pensamento como atividade prática e o discurso devem levar em conta tanto sua função comunicativa (ou social) quanto sua função intelectual ou organizadora. Na interação social, toda a atividade prática da criança é transformada, incluindo o uso de ferramentas, resolução de tarefas e atividades simbólicas em um novo nível de organização.

Assim, na ontogenia, os signos passam a mediar as chamadas linhas naturais e culturais de desenvolvimento. De acordo com Vygotsky (1984), a mente individual da criança está entrelaçada no desenvolvimento com sistemas específicos de ferramentas e sinais (gestos, linguagem, escrita etc.), que evoluíram nas sociedades ao longo da história humana.

Vygotsky (1998) introduziu os termos mediação e signo para descrever o processo no qual a cultura transforma a cognição e o comportamento da criança em um novo nível qualitativo de significados culturais, e a própria criança molda ativamente sua relação com o meio ambiente. Por sua natureza social, esses signos compartilhados culturalmente podem ser considerados convencionais (Baquero, 2001). 
A aquisição desses sistemas culturalmente compartilhados de sinais e ferramentas por meio da interação social e (individualmente) por meio da formação de funções psicológicas superiores, permite que a criança domine seu ambiente e seu próprio comportamento. Portanto, os signos crescem para mediar a influência ativa da criança em seu ambiente e em si mesma (Silva et al., 2017).

O sistema de atividades, atenção, memória e percepção da criança se desenvolve de acordo com seu crescimento orgânico e sua experiência natural do mundo, e está estruturalmente entrelaçado no limiar simbólico com o sistema de significados culturalmente compartilhados pela aquisição de símbolos mediadores (González-Rey, 2004). A aquisição do sistema de signos culturais possibilita que a criança use seu ambiente em seu próprio benefício, enquanto o comportamento de outras espécies é, de acordo com o modelo Vygotskyano, determinado, principalmente, pelas condições do ambiente. Para Vygotsky, o signo ainda é um conceito muito mais amplo do que palavras em uma língua (Viotto Filho et al., 2009).

Mesmo assim, para Vygotsky (1998), a linguagem continua sendo o protótipo de um sistema de signos, uma vez que a linguagem parece ser a base de muitos outros sistemas de signos, que também têm um efeito profundo no desenvolvimento cognitivo. O desenvolvimento das operações de signos não se limita ao desenvolvimento e uso da fala, as mudanças no desenvolvimento se manifestam de diferentes maneiras no uso de signos, que inclui também gestos, desenhos, imagens e operações práticas com diferentes objetos com os quais a criança entra em contato (González-Rey, 2004).

Diferentes sistemas de signos têm um tipo diferente de influência na estrutura da memória (Vygotsky, 1994), por exemplo, memorizar algo cortando signos em árvores difere de uma nota escrita. O nível de abstração possível em sistemas de signos difere. O nível mais alto de abstração no pensamento parece estar correlacionado, para Vygotsky (1994), ao amadurecimento social da criança nas sociedades industriais. Em outros tipos de sociedades, a abstração quase absoluta, como pensar matematicamente ou usar os chamados conceitos científicos, por exemplo, pode nunca chegar à sua plena realização.

As funções mentais superiores são o resultado da atividade mediada, na qual é realizada por ferramentas psicológicas. A principal função dessas ferramentas é que elas permitem uma certa liberdade para a mente da situação ambiental concreta, o que torna possível aos humanos organizar e construir seus ambientes em um grau muito mais alto, e em um nível qualitativamente mais alto, do que outros animais (Baquero, 2001).

Isso pode ser visto como o modelo de Vygotsky do limiar simbólico, em que os signos simbólicos são mediadores, que unem funções sociais e intelectuais, mas também, como ferramentas, são mediadores entre o ser humano e o meio ambiente. No desenvolvimento, esses dois aspectos são reunidos em atividade simbólica de tal forma que transforma toda a atividade da criança em um novo nível de organização (Rego, 2001).

\section{Como a Inteligência se Desenvolve de Acordo com Vygotsky}

A inteligência tem sido uma das temáticas centrais da Psicologia desde o surgimento desta Ciência há pouco mais de um século. É considerada sua influência sobre o saber, a competência, a tomada de decisões, a resolução de determinadas situações e a aprendizagem. Nesse sentido, a inteligência tem uma função adaptativa, permite modificar comportamentos a partir da avaliação dos resultados obtidos. Essa avaliação pode ser um simples mecanismo de associação entre estímulos e respostas, bem como, um complexo processo de análise e síntese (Gallegos, 2013).

Para a Psicologia Vygotskyana (1979) a inteligência é um produto histórico-cultural, e pode ser modificado por meio da atividade mediada pela linguagem, mesmo sendo herdada, ela também pode se desenvolver. Em essência, Vygotsky (1996) reflete que o indivíduo não nasce pronto e tampouco é cópia do ambiente externo, sendo que o desenvolvimento do conhecimento advém de uma grande influência das experiências do indivíduo. Em sua evolução intelectual há uma interação constante ininterrupta entre processos internos e influências do mundo social: só nos desenvolvemos quando aprendemos. 
Vygotsky influenciou o pensamento construtivista moderno, talvez mais do que qualquer outro indivíduo. Ele argumentou que, ao contrário dos animais que reagem apenas ao meio ambiente, os humanos têm a capacidade de alterar o meio ambiente para seus próprios fins. É essa capacidade adaptativa que distingue os humanos das formas de vida inferiores (Oliveira, 1992).

Uma de suas contribuições centrais para o pensamento psicológico foi sua ênfase na atividade socialmente significativa como uma influência importante na consciência humana. A afirmação mais controversa de Vygotsky era que todas as funções mentais superiores se originam no ambiente social. Sua abordagem da inteligência enfatizou a inteligência como uma atividade de processo, em vez de uma entidade estatal (Souza, 2011).

A teoria de que a inteligência se desenvolve em grande parte como resultado da internalização, ou seja, as crianças aprendendo o que observam no ambiente e tornando-o parte de si mesmas. O desenvolvimento ocorre em parte por meio de uma ZDP, que distingue o que as crianças podem fazer sozinhas do que podem fazer com a ajuda de outras pessoas (Costa, 2006).

Vygotsky (1979) argumentou que o desenvolvimento só pode ser compreendido dentro de uma estrutura social. O indivíduo e sua cultura estão intrinsecamente entrelaçados por meio do processo de interação. E a análise histórica das mudanças culturais é responsável pelas mudanças no desenvolvimento de crianças de diferentes gerações (Smolka et al., 2005).

Era importante para Vygotsky estudar seus objetos de pesquisa sem isolá-los de seu contexto de desenvolvimento cultural. Vendo o desenvolvimento de uma criança como um processo complexo que acontece em uma interação próxima com seu meio social, Vygotsky introduziu uma abordagem nova e abrangente que lhe permitiu observar o desenvolvimento psicológico e linguístico da criança durante as interações com outras pessoas (Souza, 2011).

Originalmente, Vygotsky (1962) acreditava que o pensamento e a fala desempenhavam funções diferentes e evoluíram de forma relativamente independente. Ele menciona uma fase pré-fala definida no desenvolvimento da inteligência e uma fase pré-intelectual no desenvolvimento da fala (Viotto Filho et al., 2009).

Vygotsky (1998) percebeu semelhanças na forma como grupos de crianças pequenas ou animais superiores se comunicam sem falar (símbolos e sinais): movimentos expressivos, gestos, expressões faciais, etc. No entanto, ele enfatizou que existem formas de pensar não associadas à fala. Vygotsky acreditava que a idade de dois anos é um ponto crítico e crucial no desenvolvimento de uma criança (Gonzalez-Rey, 2004).

Desde então, pensamento e fala começam a se entrelaçar. Vygotsky (1994) observou que essa fase é caracterizada pelo rápido aumento do vocabulário comunicativo da criança. A criança descobre primeiro a função simbólica da linguagem, compreende o significado de generalização como meio de comunicação e passa a utilizá-la para comunicação e resolução de situações (Smolka et al., 2005).

Todas as oportunidades e assistência que uma pessoa obtém para o desenvolvimento cognitivo estão enraizadas na cultura à qual ela pertence. A pessoa aprende alto nível de funções mentais por meio de atividades externas. Por exemplo, inicialmente, uma criança se move e explora o ambiente, mas gradualmente ela aprende a manipular o ambiente para se adequar ao seu propósito, encontrando soluções mais fáceis e inteligentes para os problemas (Costa, 2006).

De uma perspectiva Vygotskyana, a habilidade (ou falta de habilidade) não é inerente ou genética. Neste caso, a criança aprenderá com mais eficácia se o aprendizado estiver dentro de sua ZDP, de outra maneira, aprender fora da ZDP do aluno, ocorre pouco estímulo e, por conseguinte, não haverá desenvolvimento da inteligência como deveria (Souza \& Rosso, 2011).

\section{Principais Contribuições de Vygotsky na Educação}

Pode-se se afirmar que Vygotsky demonstra uma construção através do mecanismo de internalização: no desenvolvimento cultural da criança, que ocorrem primeiro no nível social e depois no individual; entre pessoas (interpsicológica) 
e no interior da criança (intrapsicológica) chamando para o uso de metodologia de estudo qualitativos na educação (Vygotsky, 1984). Dessa forma, a base para uma educação de acordo com Vygotsky (1998), é a cultura, a linguagem, e as relações sociais em processo de construção e reconstrução permanente. Nesse sentido, o trabalho em grupo, além de estimular a interação social, é importante na inserção no convívio social, auxiliando na superação de problemas desta ordem. Entretanto, o contato professor e aluno não pode ser dispensado, pois é o momento em que o professor pode detectar o desenvolvimento real e proximal dos alunos (Oliveira, 1993). Nesta perspectiva, estima-se o papel do educador no desenvolvimento e aprendizagem; a criança aprende desde que nasce e é capaz de estabelecer relações crescentes com os outros, com os objetos e consigo mesma (Mello, 2003).

O legado de Vygotsky na educação é duradouro e prolífico, influenciando a pesquisa educacional que vai desde o desenvolvimento infantil, o desenvolvimento da linguagem e da alfabetização, a educação bilíngue e as dificuldades de aprendizagem, para citar apenas algumas.

Em vista da presença nos escritos de Vygotsky de concepções comportamentais e construtivistas, não é surpreendente que alguns educadores tirem do trabalho de Vygotsky implicações educacionais que são comportamentais, e outros tirem implicações que são construtivistas. É importante olhar para práticas educacionais específicas elaboradas por teóricos e seus seguidores, porque essas aplicações da teoria fornecem insights sobre a própria teoria (Toassa, 2013).

O próprio Vygotsky dificilmente descreveu quaisquer práticas educacionais que considerasse consistentes com sua teoria. Em uma palestra proferida em 1933 e publicada em francês, Vygotsky (1995, p.35) especificou a necessidade de levar em consideração o fato de que a criança até a idade de três anos "aprende enquanto segue seu próprio programa" e que na idade escolar ela é capaz de aprender de acordo com os desejos do professor.

A idade pré-escolar, segundo Vygotsky, ocupa uma posição intermediária em que a criança "faz o que deseja, mas deseja o que o guia deseja" (Vygotsky, 1995, p. 36). A partir dos três anos, "a criança em idade pré-escolar é capaz de aprender na medida em que o programa do professor passa a ser seu próprio programa” (Vygotsky, 1995, p. 36).

O problema de tentar extrair implicações educacionais dessa, é que Vygotsky não especificou claramente as formas de assistência social que constituem orientação para os alunos na ZDP. A ideia de prestar assistência a uma criança é uma ideia que em si não é behaviorista nem construtivista e certamente não é nova. Portanto, pode-se conceber uma assistência diretiva e autoritária, bem como uma assistência cooperativa não-diretiva (Zanella, 2001).

Os educadores Vygotskyanos baseiam-se, particularmente, na ideia da ZDP, buscando identificar um ensino que usa a competência do adulto ou de seus pares mais capazes como guia para a participação em uma atividade. Como observado acima, essa ideia não especifica como intervir na ZDP, e os educadores vygotskyanos diferem amplamente no ensino que apresentam como modelos (Silva et al., 2016).

Em contraste com as expressões educacionais behavioristas, vários educadores interpretam a teoria de Vygotsky de maneiras compatíveis ou idênticas à abordagem construtivista baseada na teoria de Piaget. Vygotsky viu novas capacidades cognitivas para os alunos, particularmente processos mentais superiores, como resolver uma determinada situação-problema, lógica e formação de conceitos, emergindo primeiro na interação com outros antes de serem assumidos pelo aluno de forma independente (Frade, 2012).

Por exemplo, um professor pode ajudar um aluno a resolver um problema matemático com palavras, trabalhando com um conjunto de perguntas para identificar o que eles sabem e o que precisam aprender. Na próxima vez que o aluno encontrar um problema semelhante, ele repassará mentalmente as mesmas perguntas e as perguntas se tornarão uma ferramenta para o pensamento do aluno (Silva et al., 2016).

A teoria de Vygotsky foi usada para inspirar o foco em organizações interativas e colaborativas de ensino e aprendizagem que incentivam os alunos a aprender a partir das interações sociais com os colegas e com o professor. $\mathrm{O}$ ensino dialógico centra-se na co-construção do conhecimento em contextos sociais onde os alunos aprendem a usar o raciocínio 
específico e estratégias de argumentação particulares a domínios específicos do conhecimento e a elaborar, comparar e discutir verbalmente os seus conceitos em desenvolvimento (Frade, 2012).

\section{A metodologia de Resolução de Problemas (RP) na Aprendizagem sob a Perspectiva Sociointeracionista}

Nos métodos de RP, o modelo tradicional de aplicação de perguntas como parte da revisão, correção ou avaliação do conteúdo é substituído por um processo de aprendizagem interativo, que estimula a curiosidade e incentiva os alunos a participarem ativamente. Ao utilizar métodos de RP em aulas, é necessário ser consistente com o plano de ensino que considera todas as etapas do processo. Afinal, para resolver o problema proposto, os alunos precisam ir além dos conhecimentos que já possuem, estes são muito importantes na fase inicial de resolver uma dada situação (Silva, 2017).

O trabalho com RP pode mudar o papel do professor, ou seja, ao invés de entregar todo o conteúdo esperado e usar o problema como forma de avaliar se o conhecimento é compreendido, o professor assumiu o papel de um mediador, fazendo perguntas e mediando o caminho percorrido até que o aluno encontre a resposta. Tão importante quanto a RP é incentivar a discussão e fornecer ferramentas para que isso aconteça (Freitas, 2015).

Moreira (2009), menciona que Vygotsky propõe que o desenvolvimento cognitivo ocorre através da interação social, em que, no mínimo, duas pessoas estão envolvidas ativamente trocando vivências e ideias, gerando novas experiências e conhecimento. No caso dos alunos, estes são capazes de usar o conhecimento adquirido para resolver situações novas e propor soluções, lembrando aqui da ZDP, compreendida com o que separa a autossuficiência do aluno quando ele necessita de pares mais capazes.

Assim, do ponto de vista sociointeracionista, propõe-se a existência de uma janela de aprendizagem, em que o professor atua com práticas pedagógicas apresentando os conteúdos sob a forma de problemas, permitindo o avanço dos alunos no desenvolvimento real para o potencial.

Como aponta Duarte (1996), a RP tem a natureza sóciointeracionista, porque suas atividades se concentram na dialética histórica, não apenas nos interacionistas e construtivistas da obra de Vygotsky. No entanto, Vygotsky (1991) enfatizou que os conceitos espontâneos precisam atingir um certo grau de sistematização para estabelecer os conceitos científicos correspondentes. Portanto, através da teorização da resolutividade, em princípio, o conceito espontâneo, e o conhecimento científico que o sujeito e sua experiência compreenderam, já é a priori. Porém, no processo de ensino, os problemas estabelecem conceitos, que por sua vez são conhecimentos científicos que ainda não foram aprendidos.

Seu método epistemológico tem impacto no método de problematização por se basear na educação baseada no preconceito dos alunos na construção ativa do conhecimento, pois cria neles o hábito e a atitude de enfrentar a aprendizagem como um problema para o qual deve ser encontrada uma resposta (Oliveira, 1992).Este método certamente não é uma ferramenta mágica, mas é primordial e competente para utilizá-lo em um grande número de problemas, especialmente aqueles que são mais difíceis, buscando estratégias para resolvê-los. (Chaiklin, 2011).

Destaca-se ainda outro ponto relevante na aprendizagem cooperativa, em que converge na construção de processos mentais mais elevados em que a RP assume um papel de interação inter-pares ou pares mais aptos para encontrar parte de soluções e resolver problemas.

A influência de Vygotsky se insere nesta prática pedagógica com a mediação, internalização, linguagem, formação de conceitos e ZDP, que otimiza a atividade em grupo e a RP como ponto de partida. Vygotsky (1998) destaca que a RP não se enquadra como uma categoria conceitual, mas sim como um método de investigação para elaboração de conceitos.

Nesse cenário, a metodologia por RP encontra suporte na Teoria Sociocultural do Desenvolvimento Cognitivo de Vygotsky considerando que para desenvolver um conhecimento necessita-se de grupos heterogêneos quando em contexto 
escolar, ou seja, a aprendizagem humana advém de um processo social. Portanto, o professor desempenha um papel de moderador da aprendizagem, escolhendo estratégias para que o aluno encontre sentido no que está aprendendo. Se o ambiente não mostrar tarefas desafiadoras, não haverá estímulo do intelecto e o raciocínio não alcançará estágios elevados (Vygotsky 1998), em vista disso, a RP ocorre por apropriação de signos produzidos ou novos, um elo entre um estímulo provocado e a resposta do aluno, nesta conjuntura como uma ferramenta de mediação que inserida neste contexto baliza possíveis soluções aos problemas.

\section{A relação de Vygotsky com o Desenvolvimento do Aluno em um Ambiente Virtual de Aprendizagem (AVA)}

Tendo em vista que há uma grande demanda do uso de AVA (De Oliveira et al.,2012; Carminati et al., 2021; Medeiros, 2019,) este espaço virtual com várias plataformas digitais tornou-se um acesso essencial com infinitas possibilidades para implantar e implementar diferentes saberes. O uso do AVA e a criação de um portfólio aumentaram o nível de habilidade, confiança e produtividade do aluno e permitiram um maior nível de colaboração entre os membros do grupo.

Torna-se relevante trazer como o campo está trabalhando a AVA no Ensino Básico. Neste ambiente de aprendizagem, Fiori e Goi (2021), citam que há um sistema colaborativo entre professor e aluno desempenhando novos papéis. Em síntese, no que se refere à Educação, existe um debate sobre as políticas de uso de tecnologias digitais no ambiente escolar, necessitando de uma cultura de uso prudente e produtivo. Estes espaços educativos com o uso de plataformas digitais oficializadas pelas instituições de ensino, possibilitam ao professor e aluno novas formas de construção do conhecimento. As autoras recomendam que sendo a AVA uma alternativa para os desenvolvimentos dos processos de ensino e de aprendizagem e que se tenha elencadas algumas dificuldades relevantes, como por exemplo, a falta de condições financeiras para se ter uma internet estável, fica evidenciado o esforço tanto dos professores quanto de alunos e responsáveis ainda se necessita das políticas públicas para implantar esta tecnologia na rede, resolvendo estes impasses ressaltados nas pesquisas.

Observando o cenário do aporte teórico Vygotskyano, a formação do indivíduo acontece na relação sujeito/sociedade, assim um modifica o outro. Posto isto, para o AVA, pode-se dizer que tanto o computador quanto a internet são instrumentos culturais de aprendizagem que apresentam novas formas de comunicação e ou interação de preferência em ambiente escolar.

E, na concepção de interatividade no AVA há uma condução ao processo do aluno ativo em seus conhecimentos e o professor mediador deste processo, e nesta linha de pensamento se proporciona uma reflexão de como os estudos pré era computacional podem dialogar com a era moderna, assim acontecendo a interação com o computador. Na visão da autora Gama (2013), o professor organiza o AVA com atividades que levam o aluno à prática de ações compartilhadas, colaborativas e reflexivas, enquanto este último em suas pesquisas e leitura selecionam o que seja relevante para si próprios.

Há uma razão para que Vygotsky tenha mantido seguidores leais e, mesmo agora, com o avanço na educação online, suas teorias estão fornecendo um suporte útil para o desenvolvimento da pedagogia centrada no aluno. Sua teoria proporciona ciência quanto a própria visão dos alunos, por exemplo, crianças definidas por sua idade e QI versus alunos culturalmente e socialmente estimulados (Kenski, 2007).

Isso leva a formular o ideal de professor, por exemplo, modelo de comportamento versus fonte de conhecimento versus mediador, e assim por diante e, reconhecer esses papéis de aluno e instrutor na educação é fundamental se a intenção é compreender a própria tarefa no desenvolvimento do currículo em um contexto social mais amplo (Coelho et al., 2017).

Vygotsky (1986) reconheceu os processos humanos básicos que orientam o aprendizado. Nisso, ele olhou para o processo de aprendizagem, e não para o valor da informação que estava sendo aprendida. Ele teorizou que para os humanos alcançarem seu desenvolvimento cultural completo, eles devem facilitar relacionamentos significativos com os outros (Sousa et al., 2011). 
Para tanto, os educadores que usam o modelo online podem aplicar este princípio da aprendizagem mediada socialmente em sua sala de aula e abrir espaço para o fomento dessas interações em sala de aula. Algumas aplicações práticas para o ensino seriam variar os tipos de interações mediadas e não mediadas que ocorrem na sala de aula (Pulino Filho, 2005).

Os instrutores podem incorporar interação assíncrona e discussões encadeadas para interações básicas e também podem abrir espaço para instrução síncrona por meio de salas de bate-papo instrucionais, teleconferência e feeds da web ao vivo. Existem outras oportunidades para os educadores encorajarem a interação social em um contexto educacional (Sousa et al., 2011).

Os instrutores podem designar projetos que exijam que os alunos procurem profissionais e especialistas em seu ambiente imediato para concluir certas tarefas. Além disso, através do reconhecimento da diversidade inerente de experiência na sala de aula, os professores podem desenvolver oportunidades para uma troca livre de ideias em torno de tópicos guiados fornecidos pelo professor (Pulino Filho, 2005).

Desta forma, os alunos são capazes de se beneficiar de suas experiências compartilhadas e são capazes de desenvolver e testar teorias em um contexto social e, assim, tornar essas novas teorias parte de sua experiência internalizada, o próprio fundamento da aprendizagem articulado por Vygotsky (Van Der Linden, 2005).

Segundo Vygotsky (1978), os alunos são capazes de atuar em níveis intelectuais mais elevados quando solicitados a trabalhar em situações colaborativas. Com os avanços da tecnologia e as mudanças nos métodos de comunicação, a pesquisa mostrou que o uso da tecnologia da informação e do ambiente virtual de aprendizagem tem aprimorado a experiência dos alunos. Isso garantiria que os métodos usados sejam atuais e atualizados.

Para alguns, "virtual" evoca um mundo artificial que substitui a vida real. Mas os ambientes virtuais de aprendizagem não substituem as salas de aula nem as práticas educacionais existentes. Eles realçam e agregam valor à medida que estendem o espaço do ambiente físico de aprendizagem fornecendo oportunidades para expandir a imaginação de professores e alunos (Nilcimar, et al., 2018).

Segundo Pereira et al. (2016), as atividades de escrita, leitura e visualização de vídeos são favorecidas com o uso de um AVA, tanto ao professor como ao aluno no ensino de química. Os autores ainda ressaltam que o ensino presencial é marcado por métodos pedagógicos centrados no professor, ao passo que o ensino a distância busca estratégias no processo de ensinoaprendizagem que enfoquem o aluno. Ou seja, o Ensino de Química de forma à distância pode ser mais eficiente e interativo do que o ensino presencial.

A partir deste contexto, Carminati et al. (2021), desenvolveram um estudo sobre uma plataforma digital denominada GO-LAB voltada para avaliação da aprendizagem remota sob a temática: solução no Ensino de Química para alunos do $2^{\circ}$ Ano do Ensino Médio no estado do RJ, aferindo se houve aquisição de habilidades e competências.

Neste AVA, foi usado laboratórios virtuais, aplicativos educacionais e vídeos com mapas conceituais. Para verificar se os alunos compreenderam os conceitos de solução em nível microscópico, macroscópico e cálculos simples de concentração, utilizou-se a experimentação virtual e o uso de RP.

Através da teoria de Vygotsky, a maneira de apreender por AVA é um processo ativo, através de um esforço de reconstrução coletiva do antes, e este novo ambiente virtual está localizado na perspectiva de interatividade centrada na comunicação professor e aluno com participação ativa e colaborativa. Quando o autor menciona que o ser humano é herdeiro da evolução das espécies e da cultura, pressupõe- se que nos dias de hoje, o desenvolvimento do aluno é uma contínua interação com o meio em que vive, e neste caso, com a adaptação ao AVA em seu meio educacional.

Segundo Rodrigues et al. (2021), no contexto de aulas virtuais, investiga a eficiência de audiovisuais (animação e vídeos) para o ensino de configuração eletrônica nas turmas de $1^{\circ}$ Ano de Ensino Médio de um município do Estado de Mato Grosso, usando plataformas digitais Google Classroom e Meet. Houve dois momentos distintos: um encontro virtual para 
explanação da condição deste projeto e um segundo momento com o uso da AVA propriamente dita com inserção de vídeo aula interativa com animação e outro vídeo aula com materiais alternativos para a explicação do Diagrama de Linus Pauling. Após a conclusão foi enviado questionário para proceder a investigação. Ficou claro aos autores que buscar alternativas às aulas convencionais é importante para tornar as aulas atuais presenciais ou remotas, mais interativas com o apoio das tecnologias digitais, relataram ainda que muitos alunos se apoiam em outras plataformas para complementar estudos que ainda não foram de toda forma aprendidos.

Trazendo Vygotsky para este estudo, demonstra-se claramente que a ampliação ilimitada da interatividade, fontes e fluxos desses conhecimentos cumpre dizer que é uma releitura das teorias sociointeracionista, provando que o aluno desta era digital deixa de ser um sujeito receptivo para ser interativo.

Um estudo dirigido por Silva (2021), feito em uma escola pública da região do Distrito Federal dos $2^{\circ}$ e $3^{\circ}$ Anos do Ensino Médio com o uso da plataforma Google Classroom com a temática de funções orgânicas aplicada de forma híbrida. Apesar dos alunos declararem que não tiveram dificuldades com a plataforma digital, informaram que alguns professores não conseguiram utilizar na totalidade das aplicações da plataforma, e que mesmo preferindo aulas presenciais, ainda assim conseguiram entender a importância desta maneira de estudar e compreensão do conteúdo proposto.

Os sujeitos desta pesquisa concluem que a sequência didática foi válida, com a observância para estudos individuais e coletivos, assim como a procura por novos complementos por conta própria. Diante destas questões, depreende-se que os signos são um elo entre o estímulo e a resposta, agindo sob o indivíduo e não só sobre o ambiente, e ao mesmo tempo enquadra-se na ZDP com os dois níveis de potencial: o real quando o aluno pode fazer por si só e o potencial, aprendendo com os pares, claro que guardadas as proporções de que a potencialidade do aprender varia de pessoa para pessoa.

\section{O Ensino de Química em uma Abordagem Sociointeracionista}

A Química é uma Ciência teórica e experimental e uma parte importante da compreensão científica dos fenômenos da natureza e da vida cotidiana das pessoas. No entanto, na maioria dos casos, muitos alunos não conseguem estabelecer uma relação clara e eficaz entre o que eles apreciam nas aulas e suas aplicações diárias (Sangiogo et al., 2011).

A motivação para aprender Química depende de vários fatores, mas o principal fator apontado por Gatti (2013), é o método que o professor utiliza em sala de aula, pois quando o professor utiliza um método de ensino diferente do método tradicional, tais como: seminários, RP, plataformas digitais, AVA, contextualização e experimentos, estimula o interesse dos alunos em aprender o assunto, e eles são capazes de conectar o conhecimento da Química com a vida diária (Gatti, 2013).

Diante de um referencial Vygotskyano, a importância de praticar metodologias sociointeracionista na sala de aula é fator de incentivo às interações aluno - aluno e professor - aluno, onde de fato o professor será o mediador às discussões e estimulador de RP de maneira coletiva, reconhecendo a potencialidade e enriquecendo o processo de construção do conhecimento de química nas trocas e reconstrução de conceitos por parte do aluno.

A maneira como Vygotsky entende a origem e evolução da psicologia humana tem características do sóciointeracionista, pois acredita que o indivíduo adquire a linguagem no processo de interação com sua formação social. Segundo Rego (2001), a hipótese de Vygotsky levou à premissa de que o homem se constitui por meio de suas interações sociais e, portanto, ele é considerado uma relação que surge em uma determinada cultura.

Portanto, é enfatizado que os ideais de Vygotsky são completamente opostos ao pensamento ambientalista natural. O caminho para o desenvolvimento da linguagem humana não é apenas por meio da hereditariedade e maturidade, nem totalmente por meio da pressão ambiental. O que aconteceu foi desde o nascimento, a interação dialética entre o ser humano e o meio social e cultural inserido (Rego, 2001). Vygotsky (1984) acredita que a construção da função mais complexa da inteligência ocorre no processo de imersão no fundo social e cultural, que é o gestor de toda a aprendizagem. 
A teoria sociocultural da mente de Vygotsky representa uma teoria seminal e bem estabelecida em Psicologia do desenvolvimento que oferece a descrição mais robusta do desenvolvimento mental até o momento (Lantolf, 2008; Vygotsky, 1998). Três ideias seminais formam a base da teoria sociocultural de Vygotsky, uma ênfase na análise do desenvolvimento ou genética como um meio de compreender certos aspectos do funcionamento mental, a afirmação de que o funcionamento mental individual tem origens sociais, e uma ênfase na natureza mediada da ação humana (Wertsch, 1991). As implicações da teoria sociocultural de Vygotsky para a compreensão de conceitos como conhecimento e aprendizagem são profundas.

Em primeiro lugar, o pensamento Vygotskyano indica que a origem da construção do conhecimento não deve ser buscada na mente, mas na interação social co-construída entre um indivíduo mais e um menos conhecedor (Lantolf, 2008). Além disso, a construção do conhecimento é um processo mediado sócio culturalmente, afetado pelas ferramentas e artefatos físicos e psicológicos.

No debate sobre os cursos de formação de professores e projetos escolares, discute-se a importância do ensino a partir da relação interativa entre os alunos e a sociedade. Para tanto, propõem-se metodologias de ensino que tornem o conteúdo o mais próximo possível do cotidiano dos alunos. Lev Vygotsky (1986) apresenta a teoria sócio interacionista, que acredita que a aprendizagem individual ocorre por meio de sua interação com o meio social, ou seja, por meio de atividades coletivas que proporcionam a discussão e o pensamento crítico e o desenvolvimento reflexivo.

Lima (2012) evidenciou que para ter sucesso no Ensino de Química, ela precisa ser problemática, apresentada de forma desafiadora, e estimular os alunos a explorar a construção do conhecimento científico. O conteúdo deve ser apresentado ao aluno de forma a oportunizar a discussão e a interação, para que ele perceba que esse conhecimento faz parte do seu mundo e da realidade em que vive, contribuindo para uma aprendizagem que tenha significado.

Para que a aprendizagem seja relevante, o ambiente deve ser propício, ter um espaço de diálogo efetivo, respeitar o aluno e fazer com que ele se sinta parte do conhecimento. Além disso, é importante ressaltar que "a construção das aprendizagens significativas implica a conexão ou vinculação do que o aluno sabe com os conhecimentos novos, quer dizer, o antigo com o novo" (Pelizzari, et al., 2002, p. 40), dessa forma, novas informações devem estar diretamente relacionadas à experiência do aluno para construir conhecimento a partir dessas interações.

Comprovou-se a importância da formulação de propostas com base na abordagem sociointeracionista em sala de aula, para tanto, os professores desempenham um papel importante na mediação das discussões e no incentivo à resolução coletiva de problemas. Além disso, os professores incentivam a interação aluno-aluno e professor-aluno, por meio de disciplinas envolvidas em uma aprendizagem efetiva e significativa.

A interação social no ambiente de sala de aula é propícia ao desenvolvimento da autonomia dos alunos, oportunidade de se expressarem livremente e de se tornarem ativos no processo de aprendizagem. Habilidades de trabalho em equipe também são favorecidas porque o contato com outras pessoas e as conversas entre elas estão ocorrendo.

Portanto, reconhece que o potencial da teoria sociointeracionista em enriquecer o processo de construção do conhecimento em Química, promove a comunicação do aluno e a reconstrução conceitual. Enfatiza a necessidade de reflexão e aprofundamento sobre o propósito prático de desenvolver uma metodologia baseada na teoria sócio interacionista com alunos do curso de Química, que pode comprovar sua eficácia no campo da prática e como contribuinte para a formação e prática docente.

\section{Considerações Finais}

A análise documental demonstrou que o interacionismo conceituado por Vygotsky no contexto sala de aula, enriquece a construção do saber Química em um trabalho de equipe e na reconstrução dos conceitos por parte dos alunos, entendo claramente as dificuldades associadas aos conteúdos de Química que por vezes demonstram-se abstratos e complexos. 
A teoria sócia histórica possibilitou a compreensão de aspectos ligados ao Ensino de Química e o uso de Ambiente Virtual de Aprendizagem (AVA), com metodologias ativas mais modernas como a Resolução de Problemas (RP) com as múltiplas interações em sala de aula, evidenciando que as ideias de Vygotsky abrangem relações na área da Educação para a construção do conhecimento químico.

Ressalta-se que as metodologias da gestão pedagógica no emprego com AVA, exigem novas interações ao processo escolar em relação ao professor/aluno/gestor/comunidade. Dito isso, torna-se imperativo a formação profissional adequada à nova realidade da tecnologia da informação e uso dos instrumentos de aprendizagem fora da zona de conforto.

Mediante o que foi discutido, fica evidenciado que aulas híbridas ou presenciais são bem mais enriquecedoras que as remotas, pois como Vygotsky aborda em sua obra "Psicologia Pedagógica” de 1924: “o professor é o organizador do meio social educativo, o regulador e o controlador de suas interações com o educando" (p.76), ou seja, o mediador, um elo entre o aluno e o conhecimento.

\section{Referência}

Arragão, R. F. \& Silva, N. M. (2012). A Observação como prática pedagógica no ensino de geografia. Geosaberes.

Arruda, S. C. Carvalho A. A. \& Da Silva G. L. (2019) A mediação simbólica e a utilização de instrumentos e signos: práticas que contribuem para o processo ensino-aprendizagem. Anais VI CONEDU... Campina Grande: Realize Editora.

Astolfi, J. P. \& Develay, M. (2014) A didática das ciências. Papirus Editora.

Baquero, R. (2001) Vygotsky e a aprendizagem escolar. Artes Médicas.

Brito, A. C. U. (2013) Práticas de mediação de uma professora de educação infantil. São Paulo: Universidade de São Paulo.

Carminati, S. P. Dantas, L. F. S. \& Alves, T. R. S. (2021) A criação de um ambiente virtual de aprendizagem como forma de avaliação do ensino de soluções: uma proposta didática para as aulas remotas de Química. Revista Educação Pública, 21(21).

Coelho, W. G. \& Tedesco, P. C.A.R. (2017). A percepção do outro no ambiente virtual de aprendizagem: presença social e suas implicações para Educação a Distância. Revista Brasileira de Educação. 22(70).

Coelho, L. \& Pisoni, S. (2012) Vygotsky: sua teoria e a influência na educação. Revista e-Ped-FACOS / CNEC Osório, 2(1).

Costa, D. A. F. (2006). Superando limites: a contribuição de Vygotsky para a educação especial. Revista psicopedag. 23(72).

Chaiklin, S., Pasqualini, J. C. (2011) A zona de desenvolvimento próximo na análise de Vigotski sobre aprendizagem e ensino. Psicologia em Estudo. 16(4), 659-675.

De Alcântara Assunção, E. A., Barros, I.C. L. Campos, A. F. (2021) Resolução de problemas articulada a experimentação para abordagem de conteúdos químicos relacionados à temática qualidade da gasolina para estudantes do ensino médio. Experiências em Ensino de Ciências, 16(1), 740-756.

De Azevedo, T. M. (2013). Por uma aprendizagem significativa da língua materna: o ensino fundamentado em Saussure e Ausubel. Nonada: Letras em Revista, 1(20), 191-212.

De Oliveira Sousa, S.I, Schlünzen Junior, Klaus. (2012) A contribuição de um Ambiente Virtual de Aprendizagem para potencializar a colaboração no Desenvolvimento da Aprendizagem Baseada em Problemas. El Hombre y la Máquina, 40, 44-54.

Da Silva, E. R. A, Goi, M. E. J. (2020) Impressões de estudantes sobre o trabalho com resolução de problemas e temáticas em aulas de química. Revista Prática Docente, 5(2), 1057-1075.

Duarte, N. (1996) A Escola de Vygotsky e a Educação Escolar: algumas hipóteses para uma leitura pedagógica da psicologia histórico-cultural. Psicologia USP, 7, 17-50.

Fiori, R., Goi, M. E. J. (2021) Revisão de literatura em ambiente virtual de aprendizagem no Ensino Básico com uso de plataformas digitais. Revista de Ensino de Ciências e Matemática, 12, 1-24.

Frade, C. E. Meira, L. (2012) Interdisciplinaridade na escola: subsídios para uma Zona de Desenvolvimento Proximal como espaço simbólico. Educação em Revista [online], 28(1)

Freitas, J. Q. P., Goi, M. E. J., Giullianni, O. F. (2015) Resolução de problemas no ensino da matemática: uma Introdução à Geometria Fractal no Ensino Fundamental. (Monografia) Universidade Federal do Pampa.

Gallegos, W. L. A. (2013) Teoría de la Inteligencia: una aproximación neuropsicológica desde el punto de vista de Lev Vigotsky. Cuad. Neuropsicol. Santiago, $7(1), 22-37$.

Galuch, M. T. B., Sforni, M. S. De F. (2009) Aprendizagem conceitual e apropriação da linguagem escrita: contribuições da teoria histórico-cultural. Est. Aval. Educ., 20(42), 111-124. 
Gama, A. M. (2013) Fundamentos da teoria Vygotskiana para apropriação de novas tecnologias como instrumentos socioculturais de aprendizagem. Travessias, Cascavel, 6(3).

González-Rey, F. (2004) O sujeito, a subjetividade e o outro na dialética complexa do desenvolvimento humano. In L. M. Simão \& A. M. Martinez (Eds.), O outro no desenvolvimento humano. Diálogos para a pesquisa e a prática do profissional em psicologia (pp. 1-27). Pioneira Thomson Learning.

Kenski, M. V. (2007) Educação e tecnologias: o novo ritmo da informação. Papirus.

Lantolf, J. P. (2008) Teoria sociocultural e ensino de segundas línguas. Equinox Publishing.

Laudan, L. (1986) El progreso y sus problemas: Hacia una Teoría del Crecimiento Científico. Encuentro Ediciones.

Laudan, L. (1977) O progresso e seus problemas: rumo a uma teoria do crescimento científico. Tradução Roberto Leal Ferreira. Unesp.

Leal Júnior, L. C., \& Miskulin, R. G. S. (2017) Perspectivas de Resolução de Problemas por meio de Articulações entre Teoria, Prática e Conceitos sobre Comunidade de Prática. Perspectivas para resolução de problemas, 1, 305-353.

Leão, M. F., Quartieri, M. T., \& Marchi, M. I. (2013) Julgamento simulado sobre aditivos alimentares como estratégia para aprofundar os conceitos químicos. Lajeado: Revista Destaques, v.5, n. 4.

Lima, G., \& Leite, R. L. (2012) O processo de ensino e aprendizagem da disciplina de química: o caso das escolas do ensino médio de Crateús/Ceará/Brasil. Buenos Aires: Revista Electrónica de Investigación en Educación en Ciencias, v. 7, n. 2.

Lima, J. O. G. (2012) Perspectivas de novas metodologias no Ensino de Química. Revista Espaço Acadêmico.

Lima, E. R. P. O., \& Moita, F. M. G. S. C. (2011) A tecnologia e o ensino de química: jogos digitais como interface metodológica. Campina Grande: EDUEPB, p.279.

Lopes, V. G. (2016) Linguagem do corpo e movimento. Curitiba: FAEL.

Luria A. R. (1976) "Fala e intelecto de crianças rurais, urbanas e sem-teto" em. Os escritos selecionados de A. R. Luria. eds. Luria A. R. Cole M. White Plains, N.Y: M. E. Sharpe.

Medeiros, D. R., \& Goi, M. E. J. (2020) A Resolução de Problemas articulada ao Ensino de Química. Revista Debates em Ensino de Química, 6, 115-135.

Medeiros, M. F. (2019). Ambiente virtual de aprendizagem na educação contemporânea: avaliando o binômio ensino-aprendizagem a partir da análise de conceitos de aprendizagem de Vygotsky e dos princípios do método cartesiano. Revista Dissertar, 1(32).

Mello, S. A. (2003). Algumas contribuições da escola de Vygotsky para a compreensão dos problemas de indisciplina na escola. Núcleos de ensino. São Paulo: UNESP, pp. 70-78.

Mendonça, M. C. D. (1993) Problematização: um caminho a ser percorrido em educação matemática. (Tese de Doutorado). Campinas, UNICAMP.

Minick, N. (2002) O desenvolvimento do pensamento de Vygotsky: uma introdução a thinking and speech (pensamento e linguagem). In: DANIELS, H. (org.). Uma introdução a Vygotsky. Tradução de Marcos Bagno. São Paulo, Loyola, pp. 31-59.

Moraes, G. S.C., Coelho, H.G., \& De Azevedo, G. (2021) A importância do lúdico na Educação Infantil. REEDUC-Revista de Estudos em Educação (26754681), 7, 96-125.

Moreira, J. A. C. (2009) Saber docente, oralidade e cultura letrada no contexto da educação infantil análise da prática docente à luz dos autores da Escola de Vygotsky. (Tese de Doutorado). Universidade Federal do Ceará.

Nilcimar, S. S. P, F. Cabral, S. L. Q. (2018) Ambiente Virtual de Aprendizagem para a Aplicação de Atividades Didáticas Pautadas na Resolução de Estudos de Caso. Educação em Química e Multimídia.

Oliveira, M. K. (2021) Vygotsky: aprendizado e desenvolvimento-um processo sócio histórico. In: Vygotsky: aprendizado e desenvolvimento-um processo sócio histórico. 111-111.

Oliveira, M. K. (1992) O problema da afetividade em Vygotsky. In Y. de La Taille, M. K. Oliveira, \& H. Dantas (Eds.), Piaget, Vygotsky, Wallon. Teorias psicogenéticas em discussão (pp.75-84). Summus.

Pelizzari, A. et al. (2002) Teoria da aprendizagem significativa segundo Ausubel. Pec, 2(1), 37-42.

Pereira, G. A. C, Nascimento, I. S, Silva, A. M. S. (2016). Ambiente moodle de aprendizagem no ensino da química para alunos do ensino médio da rede pública. ENPED.

Pérez, L. F. M., Carvalho, W. L. P. (2012) Contribuições E Dificuldades Da Abordagem De Questões Sociocientíficas Na Prática De Professores De Ciências. São Paulo: Educação E Pesquisa, 38, 727-741.

Polya, G. (1995) A arte de resolver problemas: um novo aspecto do método matemático.

Polya, G. A arte de resolver problemas. Primeira reimpressão. Tradução e adaptação de Heitor Lisboa de Araújo. Rio de Janeiro: Interciências, 1986.

Pozo, J. I. (Org.). A solução de problemas: aprender a resolver, resolver para aprender. Artmed, 1998.

Pozo, J. I. Pérez Echeverría, M. P. (1994) La Solución de Problemas. Santillana, S. A. 
Pulino Filho, A. R. P. (2005) Moodle: Um sistema de gerenciamento de cursos. Brasília: Universidade de Brasília, Departamento de Engenharia Civil e Ambiental.

Prestes, Z. R. (2010). Quando não é quase a mesma coisa. Análise de traduções de Lev Semionovitch Vigotski no Brasil. Repercussões no Campo Educacional. Universidade de Brasília, Faculdade de educação: Programa de Pós-graduação em educação.

Prestes, Z. R. (2012). Quando não é quase a mesma coisa: traduções de Lev Semionovitch Vigotski no Brasil. Autores Associados.

Rabello, E., Passos, J., Silveira. (2011) Vygotsky e o desenvolvimento humano.

Rego, T. C. (2001) Vygotsky: uma perspectiva histórico-cultural da educação. Vozes.

Rodrigues, N. C., Souza, N. R., Patias, S. G. O., Carvalho, E. T., Carbo, L., \& Santos, A. F. S. (2021) Recursos didáticos digitais para o ensino de Química durante a pandemia da Covid-19. Research, Society and Development, 10. 1-17.

Santos, F. M. T., \& Goi, M. E. J. (2012) Resolução de problemas no ensino de química- fundamentos epistemológicos para o emprego da metodologia na Educação Básica. In: Encontro Nacional De Ensino De Química, Eneq, 16. E X Encontro De Educação Química Da Bahia, Eduqui, 10. Salvador, Brasil. Anais eletrônicos.

Serbim, F. B. N, \& Santos, A. C. (2021) Metodologia ativa no ensino de Química: avaliação dos contributos de uma proposta de rotação por estações de aprendizagem. Revista Electrónica de Enseñanza de las Ciencias, 20(1). 49-72.

Silva, C. D. (2021) Ambientes virtuais de aprendizagem no ensino remoto: trabalhando funções orgânicas com o auxílio do Google Classroom.170 f., il. Dissertação (Dissertação de Mestrado) — Universidade de Brasília, Brasília.

Silva, E. R. A. (2017) Articulação entre Resolução de Problemas e a temática drogas como proposta metodológica para o Ensino de Química. Monografia (Monografia). Universidade Federal do Pampa.

Silva, J. C., \& Hai, A. A. (2016) O conceito de Zona de Desenvolvimento Proximal na educação infantil: apropriações nas produções acadêmicas e documentos oficiais brasileiros. PERSPECTIVA, Florianópolis, v. 34, n. 2, pp. 602-628.

Silva, F. G. \& Davis, C. (2004) Conceitos de Vygotsky no Brasil: produção divulgada nos Cadernos de Pesquisa. Cadernos de Pesquisa. 34(123).

Sousa, R. P., Miota, F. M. C. S. C., And Carvalho, A. B. G. (2011) Tecnologias digitais na educação. EDUEPB.

Souza, M.T.C.C. (2011). As relações entre afetividade e inteligência no desenvolvimento psicológico. Universidade de Brasília.

Souza, A. P. De, \& Rosso, A. J. (2011) Mediação e Zona de Desenvolvimento Proximal (ZDP): entre pensamentos e práticas docentes. In: CONGRESSO NACIONAL DE EDUCAÇÃO: EDUCERE, pp. 5894-5906.

$\&$

Smolka, A. L. B, De Laplane, A. L. F. (2005) Processos de cultura e internalização. Revista Viver: Mente e Cérebro. Coleção Memória da Pedagogia: Lev Semionovitch Vygotsky - uma educação dialética, São Paulo: Duetto, pp. 76-83.

Stadler, G., Romanowski, J. P., Lazarin, L., Ens, R. T. \& Vasconcellos, S. (2004) Proposta pedagógica interacionista. IV EDUCERE: Anais.

Toassa, G. (2013) Certa Unidade no Sincrético: considerações sobre educação, reeducação e formação de professores na 'psicologia pedagógica' de L. S. Vygotsky. Estudos de Psicologia, 18, 497-505.

Tunes, E., Tacca, M. C. V. R. Bartholo Júnior, R. S. (2005) O professor e o ato de ensinar. Cadernos de Pesquisa. 35(126).

Van Der Linden, M. M. G. (2005) Diálogo didático mediado on-line: subsídios para sua avaliação em situações de ensino-aprendizagem. (Tese de Doutorado). Universidade Federal de Santa Catarina, Florianópolis.

Vygotsky L.S. (1984) A formação social da mente.: Martins Fontes.

Vygotsky, L.S. (1979) Desenvolvimento de funções psicológicas superiores. Editorial Crítica.

Vygotsky, L.S. (1998) O desenvolvimento psicológico na infância. Martins Fontes.

Vygotsky, L.S. (1962) Pensamento e linguagem. MIT Press.

Vygotsky, L. S. (1978) Mind in Society: The Development of Higher Psychological Process. Cambridge MA: Harvard University Press.

Vygotsky, L. S. (1994) The problem of the cultural development of the child. In: R. Van der Veer \& J. Valsiner (Eds.), The Vygotsky reader. Oxford, Cambridge: Blackwell. 1994.

Vygotsky, L. S. (1995) Apprentissage et développement à l'âge préscolaire. Société française, n. 2/52, pp. 35-46.

Vygotsky, L. S. (1991) Obras escogidas Volumen I. Madrid: Centro de Publicaciones del M.E.C. y Visor Distribuciones.

Vygotsky, L.S. (1992) Obras escogidas: problemas de psicologia geral. Gráficas Rogar. Fuenlabrada.

Vygotsky L.S. (1986) Thought and Language. The MIT Press. 
Research, Society and Development, v. 10, n. 13 e507101321405, 2021

(CC BY 4.0) | ISSN 2525-3409 | DOI: http://dx.doi.org/10.33448/rsd-v10i13.21405

Vigotski, L. S. (2003) Psicologia Pedagógica. Edição Comentada. Artmed.

Viotto Filho, I. A. Ponce, R. F. E Almeida, S. H. V. (2009). As compreensões do humano para Skinner, Piaget, Vygotski e Wallon: pequena introdução às teorias e suas implicações na escola. Psicol. educ. [online], n.29.

Wertsch, J. V. (1991) Vozes da mente: uma abordagem sociocultural para a ação mediada. Harvard University Press,

Yasnitsky, A. (2018) Vygotsky: An Intellectual Biography. Routledge BOOK PREVIEW.

Zanella, A. V. (2001) Vygotsky: contexto, contribuições à psicologia e o conceito de zona de desenvolvimento proximal. UNIVALI. 